\title{
Public perceptions of the introduction of the single-use carrier bags charge in Scotland.
}

\author{
OKE, A., PEDERSEN, S. and MCDONALD, S.
}

2017

Author Posting (c) Westburn Publishers Ltd, 2017. This is a post-peer-review, pre-copy-edit version of an article which has been published in its definitive form in the Social Business, and has been posted by permission of Westburn Publishers Ltd for personal use, not for redistribution. The article was published in Social Business, 7(2), Summer 2017, pages 127-154, DOI: 10.1362/204440817X14970183958041 https://doi.org/10.1362/204440817X14970183958041. 
Public Perceptions of the Introduction of the Single-Use Carrier Bags Charge in Scotland Short Title: Perceptions of the Scottish Carrier Bag Charge

\section{Adekunle Oke}

Aberdeen Business School, Robert Gordon University

Garthdee Road, Aberdeen, United Kingdom

Tel: $+44(0) 1224262000$

Email: $\underline{\text { a.o.oke@rgu.ac.uk }}$

\section{Prof Sarah Pedersen}

(Corresponding Author)

School of Creative and Cultural Business

Robert Gordon University

Garthdee Road, Aberdeen, United Kingdom

Tel: +44(0)1224 263913

Email: s.pedersen@rgu.ac.uk

\section{Prof Seonaidh McDonald}

Aberdeen Business School, Robert Gordon University

Garthdee Road, Aberdeen, United Kingdom

Tel: +44 (0)1224 263896

Email: s.mcdonald@rgu.ac.uk 


\title{
Public Perceptions of the Introduction of the Single-Use Carrier Bags Charge in Scotland
}

\begin{abstract}
Purpose: This article analyses the comments of consumers concerning the introduction of a minimum charge on single-use carrier bags in Scotland through the Single Use Carrier Bags Charge (Scotland) Regulations 2014.
\end{abstract}

Research Methods: The data analysed in this study were collected using the BBC "Have Your Say" online messageboard. This approach provided an opportunity to analyse the perceptions of consumers, using 335 responses that were posted the day the charge was announced, and 474 responses that were posted on the day of the introduction of the charge. The collected data were inductively analysed using thematic analysis.

Findings: Like many other studies of consumer perceptions of environmental policy initiatives, the results show that public perceptions of the scheme are divergent. While some perceived the scheme to be a good idea, others argued that the charge is another form of tax on the consumer.

Limitations: The study only considers the responses of those motivated to signal their opinions on the online messageboard.

Implications: The policy implications of the scheme are discussed in this paper, including the importance of public engagement through consultation when introducing market-based instruments to influence proenvironmental behavioural change.

Contribution: The paper makes an empirical contribution through the use of social media analysis techniques to create insights into spontaneously offered public opinion of the introduction of a charge on single-use carrier bags and thus offers a critique of the instrument from the consumer point of view. Further, this study contributes to the extant knowledge of consumer perceptions of market-based interventions and adds to the debate on carrier bag consumption.

Keywords: carrier bags, plastic bags, environmental legislation, consumer perceptions, reuse. 


\section{Introduction}

Plastic bags are used extensively throughout the world and are perceived as a convenient means of carrying items from one point (for example grocery stores) to other locations (such as homes). Since their introduction in the USA in 1957 (Worldwatch Institute, 2004), plastic bags have become indispensable items for producers, retailers and consumers. Their inherent properties (lightweight, low cost, water resistant, compact and durable) make them consumers' choice for carrying purchases. Although the global consumption rate of plastic bags is difficult to establish, about 10 billion bags were used in the UK alone in 2008 (Department for Environment, Food and Rural Affairs, Environment Agency, 2009) while around 3.9 billion were used in Australia in 2007 (Lewis, Verghese, \& Fitzpatrick, 2010). According to the Worldwatch Institute (2004), about 5 trillion plastic bags were manufactured in 2002, while in the USA consumers are understood to be throwing away an estimated 100 billion plastic bags annually. As a result, plastic bags are the most ubiquitous consumer goods on earth (Worldwatch Institute, 2004). With the recent exponential increase in the world population, coupled with economic practices that encourage consumerism, the use of plastic bags will intensify unless drastic measures to curb their proliferation are implemented.

The presence of plastic bags in the environment not only causes environmental nuisance (Ayalon, Goldrath, Rosenthal, \& Grossman, 2009) but is also considered to be a threat to the survival of both the terrestrial and the aquatic ecosystems (Adane $\&$ Muleta, 2011). This threat is exacerbated by the inability of plastic bags to biodegrade. For these reasons, the abundance of plastic bags has become the focus of consumer disquiet, leading both retailers and policy makers to tackle this perceived problem. Retailers have provided consumers with the means to opt out of having single-use carrier bags (often free with the purchase of goods) if they wish by introducing sturdier multi-use carrier bags for concerned consumers to purchase and use instead. Whilst these schemes have enjoyed some success (e.g. Waste and Resources Action Programme, 2012), several governments have introduced legislation which bans, or severely restricts 
retailers from providing single-use carrier bags for their customers (Convery, McDonnell, \& Ferreira, 2007).

In 2014 Scotland followed the example of a number of its European neighbours (Convery et al., 2007) and introduced a charge for single-use carrier bags with the hope of reducing their use still further. The purpose of this research is to understand consumers' (un)willingness to support the carrier-bag waste reduction scheme in Scotland by using their own carrier bags. The main aim was to investigate consumers' perceptions of the introduction of the $5 p$ charge on single-use carrier bags ${ }^{1}$ in Scotland. These perceptions concerned both the problem itself and the legislation introduced to address it.

In the sections that follow we will locate this market-based policy intervention within the extant literature on carrier bags by explaining the three main policy approaches taken to curb carrier bag use, setting out the most salient waste management issues concerning single use carrier bags, and reviewing the literature on carrier bag consumption. We will then describe the current Scottish context and explain the research approach taken to gathering data for this study. The next part of the paper is dedicated to setting out these data and then analysing them with respect to the three strands of literature identified earlier. Finally we will draw conclusions and implications from this analysis for research and practice going forward.

\section{Plastic-Bag Reduction Strategies: a review of the literature}

In this section we will give an overview of three strands of literature which need to be drawn together in order to consider plastic bag reduction strategies: policy, consumer behaviour and waste management.

\footnotetext{
${ }^{1}$ According to the Single Use Carrier Bags Charge (Scotland) Regulations 2014, a single use carrier bag includes all types of carrier bags (such as paper \& plastic) that are supplied to carry goods from point of sale and with the intention that they are to be used once.
} 


\subsection{A policy perspective}

Different countries across the world have adopted, and are still adopting, various strategies to influence consumer behaviour towards the environment in general, and plastic bags in particular. In this section we consider some of the main concerns of the policy literature on the topic of single use carrier bags.

With respect to changing consumer preferences for single-use "lightweight" carrier bags, three main approaches are taken: voluntary efforts; levies or taxes; and total bans (Clapp \& Swanston 2009). Commentators suggest that a combination of different strategies may be required to influence proenvironmental behaviours (De Young, 1986; Ebreo \& Vining, 2001).

In order to address the environmental effects of plastic bags use, voluntary measures were observed to be effective in Australia (Cherrier, 2006), Ireland, Northern Ireland (Department of the Environment, 2013) as well as in Scotland (Waste and Resources Action Programme, 2012). Rather than forcing consumers towards anti-consumption of plastic bags (Shar, Hoj \& Wheeler., 2010), voluntary efforts are more influenced by moral and ethical as well as social norms (Cherrier, 2006). Behaviours can be more internalised when they conform to actors' personal values and norms (Hage, Söderholm, \& Berglund, 2009), and thus these efforts may be more effective in comparison to a forced approach through a marketbased instrument, which might encourage defiant acts as a result of perceived psychological reactance (De Young \& Kaplan, 1988). Some research suggests that voluntary efforts may serve as a "foot-in-the-door" mechanism to recruiting consumers to the scheme (Thøgersen \& Crompton, 2009; Poortinga, Whitmarsh, \& Suffolk, 2013).

Although voluntary efforts, by appealing to consumers' ethical/moral obligations, may be appropriate (Cherrier, 2006), it is suggested that regulation (Lewis et al., 2010) and levies may be required to change consumers' plastic-bags use behaviour. The rationale is to internalise all the externalities associated with plastic-bag use through the imposition of a tax (Convery et al., 2007), as plastic-bag litter could be conceived as a market failure. In Europe, for example, Belgium, Denmark, France, Germany, Italy, Ireland, Northern Ireland, and Wales have adopted a market-based approach and imposed minimum charges on the 
consumption of single-use carrier bags (Convery et al., 2007). In Ireland, a minimum charge of 15 cents per carrier bag was introduced in 2002, which was later increased to 22 cents in 2007 with the intention of reducing plastic-bag usage to 21 bags per capita each year (Department of the Environment, Community and Local Government, undated). In a similar development, the Welsh government introduced a minimum charge of 5 pence on a single-use carrier bag in 2011 (Poortinga et al., 2013). According to the Department of the Environment (2014), plastic-bag use in Northern Ireland significantly reduced by $72 \%$ in $2013 / 2014$ following the introduction of a minimum charge in 2013. This percentage accounted for the reduction of about 215 million bags in the reference year and generated a total sum of about $£ 4.17$ million (Department of the Environment, 2014). Such an achievement is not limited to Northern Ireland: all the countries where plastic-bag levies or bans have been introduced have experienced similar scenarios.

Although there were concerted voluntary efforts to reduce plastic-bag usage in Northern Ireland before the levy was introduced (Department of the Environment, 2013), the exponential reduction in plastic-bag use demonstrates the consumers' willingness to participate in the scheme. On the other hand, the levy may not completely explain the observed changes in consumer behaviour or the reduction experienced in the use of plastic bags in Northern Ireland since carrier-bag usage was reduced by $48 \%$ between 2006 and 2009 following a voluntary agreement ${ }^{2}$ in 2006 to reduce carrier-bag usage in the UK by $50 \%$ (Waste and Resources Action Programme, 2012). It should also be noted that the impact of this levy on pollution or littering from plastic bags is yet to be determined empirically. As a result, it is difficult to confidently establish whether the strategy has achieved and/or is achieving its intended objectives. A further issue raised about the levy approach to carrier bag reduction is that the effects of the levy may deteriorate over time, as was found to be the case in South Africa (Dikgang, Leiman \& Visser, 2012).

\footnotetext{
${ }^{2}$ A voluntary agreement between the Scottish Government, Defra, the Welsh Assembly Government, and the Northern Ireland Department of the Environment with the British Retail Consortium (BRC) and its supermarket members was entered into in 2006 (Waste and Resources Action Programme, 2012).
} 
Contrary to the adoption of a levy in shaping consumers' plastic bags behaviour, grocery shopping bags (especially plastic carrier-bags) have been banned in some other countries. For example in the USA, about 132 cities across 20 different states currently enforce complete bans on plastic bags (Larsen \& Venkova, 2014). In addition, total bans are enforced in Bangladesh, Brazil, China, and some countries in Africa, including Botswana, Ethiopia, Kenya, South Africa, Somalia, Rwanda and Uganda (Synthia \& Kahir, 2015; Chida, 2010). The first total bans were driven by locally significant concerns for the protection of animals, reduction of litter in tourist areas and other problems such as blocking drains during seasonal flooding (Clapp \& Swanston, 2009).

\subsection{A consumer perspective}

In this section we will consider how the consumer behaviour literature has addressed the issue of single use carrier bags. Much of the discussion of carrier bags in the green consumer behaviour literature is restricted to mentioning it as part of a wider set of consumer sustainable behaviours for (see for example Gilg, Barr \& Ford, 2005). Sometimes the avoidance of carrier bags, or the use of reusable bags is used as an indicator of an individual's (Cherrier, 2006) or retailer's commitment to sustainability (see for example, Meriem \& He, 2011). However there are a few examples of studies that centre on carrier bag use from a consumer behaviour perspective.

Internationally, consumer behaviour researchers have examined consumer perceptions and behaviours in relation to the different policy approaches outlined in the previous section (voluntary reduction, tax or levy on bags, complete ban). Voluntary use of a plastic bag fee by some supermarkets in Madeira has been effective (Luis \& Spinola, 2010), for example. Another study found that asking consumers whether they need a bag in Japan led to a decrease in plastic bag use (Ohtomo \& Ohnuma, 2014). Musa et al (2013) surveyed consumer preferences in England and found that 45\% would prefer single-use carrier bags. 
There are a small number of studies which aim to unpack the social meanings of reusable bags. Within the fashion literature there are (albeit very limited) discussions of the Anya Hindmarch "I am not a plastic bag" bags (see for example Beard, 2008) which consider their meaning, sometimes contrasting mainstream perceptions that the bag signifies ethical behaviour, with points made by industry commentators that they were not ethically sourced. The most detailed treatment of this issue is in a study of Australian shoppers by Cherrier (2006). By qualitatively studying individuals using re-usable bags in a context where this behaviour was entirely voluntary, she was able to draw out the social meanings that these shoppers ascribed to the bag choices made by themselves and others. She found that the use of these bags reinforced ethical consumer identities, creating a virtuous cycle of behaviour, self-identity narratives and reinforced behaviours which in turn reinforced identities for those consumers.

All of these studies are set in contexts where the consumer is free to select their position on plastic bags and the most commonly cited 'cost' is in terms of perceived personal guilt and/or social disapproval. However studies have also examined the effects of introducing a levy or tax on bags on consumer perceptions and/or behaviours. Muralidharan \& Sheehan, for example, found that US consumers were more likely to respond to a message framed as a tax rather than a fee. Proposed measures to curb, tax or ban the use of carrier bags has been a contentious issue in some jurisdictions, with public opinion being a major driver in their success or failure of their introduction. In fact early proposals for this legislation to be introduced in Scotland in 2005 were withdrawn over contested environmental benefits of a ban and worries that it would simply increase the sales of plastic bin bags (Ritch, Brennan \& MacLeod, 2009).

Synthia and Kahir's (2015) study on the practices of shoppers in Bangladesh following the ban on singleuse carrier bags found shoppers, retailers and manufacturers still finding ways to use, distribute and make the banned bags and that although the replacements that had been adopted were perceived as more environmentally friendly by consumers, that they were often similar or worse in terms of environmental impact. 
Two previous studies are of particular relevance to this research. Poortinga et al. (2013) conducted a very interesting study of Welsh consumers before and after the introduction of a charge for single-use carrier bags. They were also able to compare this with carrier bag usage with English consumers, where no charge was in place, and found that although usage decreased in both regions, the decrease was more significant in Wales. This study suggests the difference between raising awareness and actual policy intervention. Interestingly, it also showed that consumers were more positive about the legislation following the ban than before it was brought in.

Similar findings were uncovered by Sharp et al. (2010), in their study of consumer perceptions before and after the ban on single use plastic bags by the state of South Australia in 2006. They first spoke to consumers prior to the ban, and characterised them into three groups: those already using reusable bags consistently before the ban came into force, using them but inconsistently and not using them at all. Echoing the findings of Poortinga et al's (2013) Welsh study, they found that most consumers who were not already using reusable bags before the ban was put in place, were less resistant to the ban after it was in effect than they had been before it took effect, although they did find a small group who were more negative after than before the ban. Following the ban, around a third of those forced to change their behaviour still held attitudes which were not environmentally friendly. This led them to conclude that although a proscriptive ban on bags can create anti-consumption behaviour, it does not necessarily change attitudes.

\subsection{A waste management perspective}

From a waste management perspective, the case for the relative environmental damage of plastic carrier bags compared with other materials is contested. It is not a straightforward, mono-dimensional argument, but it is actually complex and multi-faceted. For example, plastic bags are the by-products of petroleum products and available in different compositional formats, including High-Density Polyethylene (HDPE), Low-Density Polyethylene (LDPE), and Polypropylene (PP) (Department for Environment, Food and Rural Affairs, Environment Agency, 2009). As no virgin resources are utilised during their production, it can be 
argued that plastic bags enable the practical re-processing and re-utilisation of the by-products of petroleum products that might otherwise end up in landfill (Bell \& Cave, 2011; Environment Agency, 2011; Musa, Hayes, Bradley, Clayson, \& Gillibrand, 2013). According to Worldwatch Institute (2004), the production of paper bags uses around $40 \%$ more resources (energy and water) than the production of plastic bags. In addition, it has been estimated that other carrier bags would have to be reused several times (See Table 1 below) in order to have a comparative or lower global-warming potential than conventional HDPE carrier bags.

\section{Table 1}

\begin{tabular}{|l|l|l|l|l|}
\hline Table 1: Global Warming Potential of HDPE Bags in relation to other Carrier Bags \\
\hline Carrier bags & $\begin{array}{l}\text { Without } \\
\text { secondary } \\
\text { reuse } \\
\text { (Number of } \\
\text { times) }\end{array}$ & $\begin{array}{l}\text { 40.3\% reused } \\
\text { as bin liners } \\
\text { (Number of } \\
\text { times) }\end{array}$ & $\begin{array}{l}\text { 100\% reused as } \\
\text { bin liners } \\
\text { (Number of } \\
\text { times) }\end{array}$ & $\begin{array}{l}\text { When used 3 } \\
\text { times } \\
\text { (Number of } \\
\text { times) }\end{array}$ \\
\hline Paper bag & 3 & 4 & 7 & 9 \\
\hline LDPE bag & 4 & 5 & 9 & 12 \\
\hline $\begin{array}{l}\text { Non-woven PP } \\
\text { bag }\end{array}$ & 11 & 14 & 26 & 33 \\
\hline Cotton bag & 131 & 173 & 327 & 393 \\
\hline Source: Environment Agency (2011). \\
\hline
\end{tabular}

For example, HDPE carrier bags that are used once without any secondary usage possess 131 times less global-warming potential in comparison to cotton bags and three times less potential than paper bags (see Edwards \& Meyhoff, 2011 for extensive analysis). This raises some practical questions about why the restriction through levies or outright bans on the use of plastic-carrier bags is imposed. Another question is whether cotton carrier bags (such as bags for life) could be re-used enough times to compensate for the carbon footprint acquired during their production and transportation. Obviously there is an unquantifiable consumer behaviour element here: just because something could have less environmental impact because it has the potential to be used many times does not mean that it will. 
While these questions remain unaddressed, there are other effects to consider, such as the persistence of plastic bags in the environment, and in particular their potential to be airborne due to their light weight. This can result in environmental pollution, the spoiling of natural landscapes, and could eventually cause a threat to (and/or loss of) aquatic and terrestrial animals, including humans (see Adane \& Muleta, 2011; Lewis et al., 2010; Musa et al., 2013; Ritch, Brennan, \& MacLeod, 2009). Taken together, these attributes have resulted in mixed perceptions amongst environmentalists concerning the consumption of single-use carrier bags and their effects on the environment.

\subsection{Summary}

Carrier bag use is a complex and contested issue. One way to measure the success (or otherwise) of any specific policy intervention would be to count the number of carrier bags used over time. However, we argue that even if the policy intervention is producing the desired outcome, it is extremely important to understand consumer perceptions of both the initial problem and of the scheme implemented in order to assess not just whether, but how and why the instrument is (not) producing the desired effect. In order to design appropriate strategies, and transfer best practice, it therefore is necessary for policy makers and all stakeholders to understand consumers' perceptions. As a result, the focus of this research is to understand and explain consumers' perceptions concerning the adoption of a regulatory framework and a market-based instrument in influencing plastic bags use behaviour following the introduction of the levy in Scotland.

\section{The Scottish Context}

Prior to the introduction of the single-use carrier bag charge in Scotland in 2014, there was a voluntary effort to reduce plastic bag consumption which was backed by both the Scottish Government and major supermarkets, similar to the situations in Wales and Northern Ireland (Waste and Resources Action Programme, 2012). Nevertheless, following the experiences from Ireland, Northern Ireland and Wales, the Scottish government introduced regulations enforcing a minimum charge of $5 \mathrm{p}$ on single-use carrier bags 
in Scotland. The Single Use Carrier Bags Charge (Scotland) Regulations became effective on 20 October 2014 (Zero Waste Scotland, 2014).

In order to encourage consumers to reuse carrier bags and reduce their perceived effects, the Regulations required retailers (food and non-food) in Scotland to charge a minimum of $5 p$ for each single-use carrier bag. Following its introduction, anecdotal evidence (Zero Waste Scotland, 2015) suggests a sharp reduction of about $80 \%$ in plastic-bag use in Scotland and highlights the effectiveness of market-based instruments in influencing consumer behaviours. Many Scottish retailers have chosen to pass the revenues on to charities. A similar levy was introduced in England on 5 October 2015 with an anticipated benefit of up to $£ 780$ million to the UK economy and about $£ 730$ million for good causes while saving about $£ 60$ million in the litter clean-up budget within the next ten years (Department for Environment, Food and Rural Affairs, Environment Agency, 2015).

As a result, it is now illegal throughout the UK to issue free single-use carrier bags to consumers, although there are a few exceptions (Scottish Parliament, 2014, p. 7) such as wholly or partly unpackaged goods and/or food items.

\section{Research Design}

Following the announcement of the charge in Scotland, the British Broadcasting Corporation (BBC) published a series of articles on its "Have Your Say" online message board regarding the Scottish government's intentions. The "Have Your Say" webpages are part of the BBC's wider embrace of so-called citizen or grassroots journalism in an attempt to fully engage with its audience via social media rather than to purely broadcast to them. Users are encouraged to engage with the BBC in a variety of ways, including sending in photographs, videos and news stories; following and commenting on BBC news via social media, including Twitter, Facebook, Instagram and WhatsApp; and commenting on current news stories on the "Have Your Say" webpages. In this way the viewers or listeners of BBC programmes are encouraged to 
become part of the news-making process itself, or at least to join the public sphere of debate by posting their views underneath articles written by BBC journalists and posted online. This article analyses comments left by readers of two of these articles, one published on 28 June 2013 before the implementation of the charge and another published on 20 October 2014, the start date of its implementation. These two articles, which were written by $\mathrm{BBC}$ journalists, provided opportunities for the public both within and outside Scotland to engage in active discussion using the "Have Your Say" message board. In this article, the views and opinions of the participants concerning the introduction of a minimum charge on single-use plastic bags in Scotland that were posted underneath these two articles are analysed and presented.

The two articles were selected because of their timing: just before the implementation of the charge; and on the day when the levy became effective. Data collection and analysis were performed using a narrative and interpretive qualitative approach, reading through all comments several times and coding them thematically.

The use of Internet-based discussion boards for data collection is governed by different epistemological, logistical and ethical perspectives than those that apply to real-time focus groups or interviews (Markham \& Buchanan, 2012). Following the recommendations of the Association of Internet Researchers ethics working committee, the discussion forum on BBC's "Have Your Say" is considered to be in the public sphere since it is not password protected. This was a purely observational study with no attempt made to contact posters or solicit any further personal details.

The advent of social media has provided opportunities for 'the people formerly known as the audience' (Rosen, 2006) to engage in media production. As Lessig (2004, p.37) points out, in comparison to mass media, which was 'read only', social media offers the opportunity to 'read and write'. Online discussion forums provide a place where a reader can become a commentator, stepping into the public sphere, albeit anonymously and briefly. However, it is important to be aware that this does not mean that comments on a $\mathrm{BBC}$ website can be seen as representative of anything other than the opinions of the commentators. As Quinlan, Shephard, and Paterson (2015) point out in their own analysis of "Have Your Say" comments 
relating to the Scottish Referendum, social media is likely to give a greater representation of the points of view of the young and, in certain circumstances, male voices may be louder than female ones. The BBC online audience tends to come disproportionately from the $\mathrm{ABC} 1$ social category, with $55 \%$ of this group using BBC online compared to only 34\% of the C2DE group (BBC Trust, 2013, pp. 79-81, cited in Quinlan et al., 2015, p.196). Nonetheless, social-media engagement offers an opportunity for members of this audience to engage in debate about issues of the day outside their own family and friends and on a public, albeit moderated, platform provided by a national broadcaster.

\subsection{Data Collection}

The first data collected were comments posted on 28 June 2013 in response to a BBC website article titled "Scottish Government Plans Charge for Plastic Bags" following the announcement of the introduction of the plastic-bag charge by the then Scottish Environment Secretary, MSP Richard Lochhead. In total, 335 comments were posted on the messageboard in response to the article, 27 of which were deleted by the moderator for violating house rules, giving a data set of 308 useable comments posted on the day the levy was announced. The second tranche of data was made up of comments made in response to an article titled "Minimum Charge for Carrier Bags in Scotland Introduced" published on the BBC website on 20 October 2014. This generated 474 comments, with 18 comments being deleted by the moderator for breaching the $\mathrm{BBC}$ house rules. As a result, the remaining 456 comments made on the day the levy was introduced were considered valid for this study. For both samples, all the comments made from the time the article was published online until the last comment of the day were recorded. In total, 764 comments from both publications were considered valid and analysed for this present study. Although this research is the first known study to adopt this data-collection approach to investigate pro-environmental behaviours, a similar data-collection approach was adopted by Rowe, Hawkes, and Houghton (2008) to investigate the public's reaction to avian influenza in the UK. In addition, this approach is similar to Shanahan's (2010) datacollection method used to analyse expert-based (scientist) and non-expert-based (non-scientist) comments about online scientific publications in a Canadian national newspaper. 
No socio-demographics or contact information for the participants were available on the messageboard. Consequently, the study population, including the sample frame for the current research, could not be established. Based on the IDs (many of which were pseudonyms) of the participants, multiple responses were identified, although no effects of these responses on the outcome of this research were observed. However, the number of comments was observed to be inflated by multiple responses, which may influence the quantity rather than the quality of the retrieved comments. No particular comment was posted more than once (or re-posted) by the same or other participants. While it was difficult to establish sample bias, this research assumed that the majority of participants were those who had a genuine interest in waste management and/or those who were (or could be) affected by the levy.

\subsection{Data Analysis}

Data analysis was performed inductively without pre-defined themes in order to better capture the perceptions of commentators concerning the introduction of the levy on single-use carrier bags in Scotland. In order to generate the emerging themes from the data, a sequential approach whereby the emerging themes from the first tranche of data informed the analysis of the second dataset, was adopted. As a result, thematic analysis (Bryman, 2012), where the contents of the transcripts from the BBC "Have Your Say" message board were downloaded and coded according to the emerging themes or labels from the data, was performed. The data-analytical process employed in this research involved different levels. These included data management, abstraction and interpretation (Ritchie, Lewis, Nicholls, \& Ormston, 2013). Accordingly, the data-management phase was sub-divided into different stages and included: data preparation, data labelling and data itemising (or sorting). This phase was followed by data abstraction and interpretation, where different categories were constructed in order to identify linkages between the comments that explicitly aligned with the emerging patterns. This analytical process was independently performed on the two sets of data but their findings were later triangulated and after careful consideration by the research 
team, it was found that the same set of themes was present in both data sets. The two data sets were therefore amalgamated and are presented as a single data set in the analysis presented in the next section.

\section{Findings and Discussion}

In this section we will set out the findings and discuss them with respect to the issues found in the extant literature(s) identified above.

Overall, the findings suggest that the participants' perceptions towards the levy were mixed and also contradicting. This is not unusual when influencing human pro-environmental behaviours using this type of intervention. For example, different levels of awareness and enthusiasm were reported when a similar levy was imposed on shopping (paper and plastic) bags in Washington D.C (Gowen, 2010). Nonetheless, seven different themes (see Figure 1) reflecting the perceptions of consumers based on their lived experiences with carrier bags were identified from the two data sets.

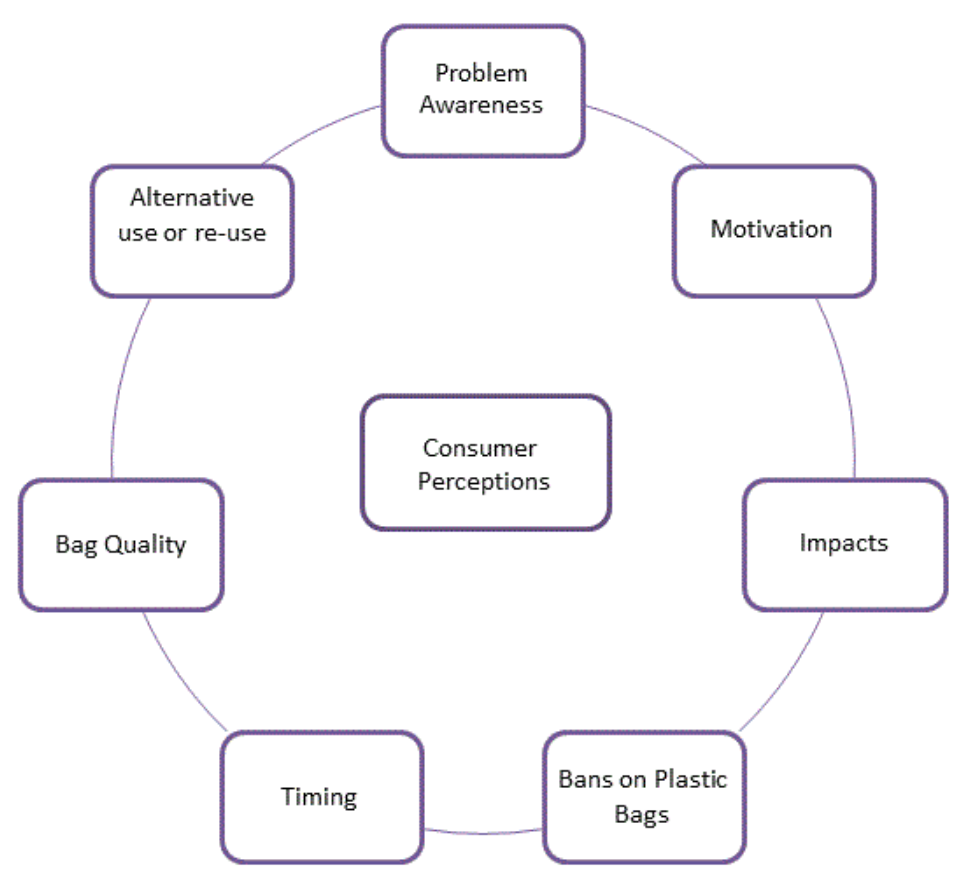

Fig. 1: The Participants' Perceptions. 
These themes offer an in-depth explanation and understanding of how the levy was perceived by the participants. In the sections that follow each theme will be discussed in detail, using illustrative quotes from the data.

\subsection{Problem awareness}

The findings from this research showed that most of the participants were aware or had substantial knowledge of the environmental and health implications of plastic-bag litter. As a result of the level of the participants' awareness concerning the effects of plastic bags littering, some participants were puzzled by the over-reliance of UK consumers on single-use carrier bags, and especially by the over-consumption of plastic bags in the UK. This was reflected in most of their comments. For example some participants stated that:

"It's disgraceful that the UK still allows the use of plastic bags at all! I'm amazed that people think it's OK in this day and age to use these ecological time bomb just for their convenience."

"We are ruining some beautiful places and just because we can't always see it happening we fail to care." Participants demonstrated awareness of the magnitude of plastic-bag waste being generated by consumers in the UK. They were aware that the current rate of recycling in the UK is low compared to the amount of waste being sent to landfill. This was corroborated by Priestley's (2016) briefing report on household recycling rates in the UK. Although some participants were re-using their plastic bags before the levy was introduced, they were aware that the current re-use approach was not sustainable as a result of the uncertainties about the long-term environmental effects of single-use plastic bags.

"The amount of plastic bags that go to landfill is shocking and we don't really know how plastic will effect the environment in the longer term."

"They are the second greatest litter contributor after plastic bottles and tin cans."

Some participants demonstrated a high level of awareness concerning the decomposition rate of plastic bags and their environmental effects. 
"Plastic bags do not biodegrade. They get damaged and disintegrate but they are still there. Even if you reuse them, they still don't degrade in landfill. . . A thousand years from now it will be still be polluting the environment."

In addition, other comments demonstrated an awareness of the extent of fly-tipping in Scotland and discussed the effects of this on Scotland's landscape, beaches, coastline and parks.

"Having visited Scotland the amount of litter takes some beating compared to the rest of Europe... People, it seems are just not interested in the cleanliness of where they live, and have little interest in reusing or recycling."

"Scotland's towns and countryside are treated as rubbish dumps by a large number of anti-social scum!"

Note that the first of the above comments was evidently from a visitor to Scotland rather than someone who lived there. The BBC website attracts a broad audience and therefore not all of the comments regarding the Scottish plastic-bag levy came from people who would be directly affected by it. Comments on an environmental issue therefore allowed others to criticise the behaviours of some of those living in Scotland - the 'anti-social scum' - under the guise of caring for the environment. The use of social media is notorious for the ease with which some users can 'flame' others, using aggressive language, or ranting, putting across only their point of view without being willing to listen to the other side. As Shephard et al. (2014, p. 38) point out, such flaming can stir up hostility, thus detracting from serious debate, and can "also have unintentional consequences such as fuelling the perception that a national side is being attacked".

Commentators were also aware of the detrimental effects of plastic bags on terrestrial and aquatic animals and how these were worsened by the lightweight and aerodynamic attributes of plastic bags.

"I'm always amazed how plastic bags get into the oceans around the world? Animals suffer horrendous injuries from our Rubbish."

"Plastic bags are light and picked up by the wind easily and end up everywhere in the landscapes and oceans causing suffering to animals." 
However, some participants' comments demonstrated an understanding that plastic bags can be considered more environmentally friendly than other carrier bags, especially paper bags. The comments were supported by the Environment Agency's (Edwards \& Meyhoff 2011) report on the impacts of carrier bags, as presented in Table 1 above. This understanding might have negative effects on the adoption of bringing their own carrier bags instead of buying one as people may not perceive a need for the levy.

"Plastic bags are more environmentally friendly than paper ones."

"In fact the supermarket bag degrades faster and is more eco-friendly!!"

Further, some comments challenged the amount of headlines plastic bags were generating, and also repeated the views that plastic bags possess a lower ecological (or carbon) footprint as no resource (besides the byproducts) is consumed during their production.

"Plastic bags make up a tiny percentage of total waste so why do they attract so much attention?

"Plastic bags have a lower carbon footprint than paper bags or cotton bags or supermarket bags for life. So this will increase the amount of greenhouse gases as we switch behaviour towards such bags!!”

In general, the comments of the participants demonstrated a diversity of opinions and beliefs about the environmental impact of plastic bags. From the comments, the level of the participants' awareness concerning environmental problems associated with plastic-bag littering is encouraging. Government campaigns and a green marketing approach might tap into this understanding in order to influence consumers' behaviours toward the levy, including their willingness or intention to use their own bags rather than purchasing new bags for each shopping trip.

Considering the findings of previous research (such as Garcés, Lafuente, Pedraja, \& Rivera, 2002; Grodzińska-Jurczak, Tomal, Tarabuła-Fiertak, Nieszporek, \& Read, 2006), one can speculate that a high level of awareness of problems associated with plastic-bag use (or littering) might influence consumers' willingness to bring their own shopping bags instead of purchasing single-use carrier bags at the till. However, Adane \& Muleta (2011) argued about the increase in plastic bags use despite the increasing level 
of awareness of its effects. As a result, awareness of the plastic bags issues may not be sufficient in deterring consumers from purchasing single-use carrier bags.

\subsection{Motivation for the introduction of the charge}

According to the report published by the BBC on 20 October 2014, an estimated 800 million single-use plastic bags were consumed annually in Scotland, and a high percentage of these ended up in landfill. As a result of the environmental and health threat, it is understandable that the government tried to reduce the amount of plastic bags being used in Scotland. On the other hand, the 28 June 2013 report published by the $\mathrm{BBC}$ quoted a $\mathrm{CBI}$ spokesperson stating that there had already been a $40 \%$ reduction in plastic-bag usage in Scotland due to voluntary initiatives. In the light of these contrasting views by the major players in the industry, the views and perceptions of consumers concerning the levy are analysed and presented in this section.

Three contrasting groups of motivations were found in the data: some participants evidently considered that the introduction of the levy was motivated by a perceived opportunity to generate funds (financial reasons); some felt the motivation was political; whilst others felt that it was motivated by a desire to enhance environmental protection.

\subsubsection{Economic motivation}

Some participants rejected the claim by the government that the levy was introduced due to a concern for the environment. Instead, many participants perceived the levy as another form of tax that might inflict unnecessary burdens on consumers.

"Yet another tax on hard working law abiding people."

“...simply another income generator disguised as an evil "green" tax..." 
This may be informed by a similar levy in other jurisdictions (for example the Republic of Ireland) where the levy has been labelled as a tax (see Convery et al., 2007 for a review).

In refuting the environmental motivation as stated by the government, one participant argued further that "since recycling is now widespread and plastic bags can be recycled, I'd like to know the mentality behind this charge". Other participants suggested that taxing businesses, especially plastic-bags producers, instead of consumers would be more reasonable and easier to implement.

"What would be easier is to tax carrier bag production not purchases; that would save time and money."

While the levy was perceived by some as another form of tax, there were suggestions that it could attract more support if the revenue was designated for developmental projects instead of donating the proceeds to charities or good causes. This might serve as a barrier for not supporting the scheme as many participants perceived that only businesses and charities would benefit from the levy.

"I would have supported the principle if it was a tax - with the proceeds going towards the betterment of society - with destinations determined by electorally-accountable bodies."

Nonetheless, some comments signified support ('It's not a tax - you can always take your own bags, which is the whole purpose of the plan"), anger ("this is pathetic because we pay council tax so we should at least get a flaming plastic bag!") and emotion ("less insulting to public intelligence if government just come clean that it is another indirect tax, \& spare us the platitudes about environment \& recycling") as provoked by the imposition of the levy.

It is interesting to note that there is an implicit assumption within the data that the charge is income for the government despite the fact that the government has made it clear that the charges are to be accrued to the retailers and have indicated that they are keen to see any income donated to good causes (http://carrierbagchargescotland.org.uk/). This may produce a knock-on effect on consumers' behaviours and consequently enhance their willingness to use own bag rather than purchasing one at the tills. In addition, there is a tendency for consumers with strong environmental concern/values to support the scheme 
despite the mixed-feelings as well as the trade-offs (Davidson, Martin, \& Treanor, 2009) involved in using their own bag and/or purchasing carrier-bags for each grocery trip.

\subsubsection{Political motivation}

A number of respondents felt that the tax was politically motivated. These comments were overwhelmingly negative, suggesting this legislation as evidence of the failure of government at either the Scottish (led by the Scottish Nationalist Party (SNP)) or UK (led by a coalition government that included the Liberal Democrat party) level:

"Thank your SNP for more draconian state control from the communist party". “...another ill considered Libdem tax...”

Some commentators suggested that the introduction of the tax was either in contrast to, or indeed to deflect from, tackling what they perceived as bigger political problems:

"Typical SNP government, avoiding the big problems and just making life more expensive and less convenient for the majority in small ways"

"Unbelievable. We have wars breaking out everywhere, a constitutional crisis, Ebola, youth unemployment etc etc, and yet our politicians have found time to debate and implement charges on carrier bags."

Most of the people who cited political motivations seemed to focus their comments on the efficacy of specific political parties (or individuals within them) rather than the legislation being introduced. Many of these comments were vehement in their nature, and suggest an interesting public framing of the new levy as a political move. The comments suggest that this legislation can be seen as part of a broader (distrusted) move to solve problems through the introduction of specific taxes and this implies that at least some commentators feel that the kind of behaviour change at the heart of this legislation should be a private rather 
than public concern. Further these comments suggest that the problem this legislation addresses is a trivial one. Most felt that environmental problems per se were trivial but a small minority suggested that carrier bags were a trivial part of an important environmental problem compared with, for example, fracking.

\subsubsection{Environmental concern}

In comparison to economic concerns, environmental or environmental-related factors were mentioned less by the participants. However, while there were arguments against the environmental rationale, there were also comments that suggest that an environmental motivation was plausible. For example:

"They are a disproportionate cause of litter and environmental degradation."

"This is good news, carrier bags are the biggest middle finger ever to the environment. Everyone has a duty to be reduce their carbon footprint."

This shows that the views concerning the levy in terms of environmental justification were divergent and suggests that environmental concern alone was not perceived to be a sufficient explanation for the introduction of the levy in Scotland. It may also suggest that the participants were less convinced about the efficacy of the levy in addressing the issue of plastic waste since many did not perceive plastic bags to be a major environmental problem in Scotland. Although consumers may feel resentful and unconvinced about the levy, the attitudes seem somewhat in line with other research findings (Gowen, 2010), although studies suggest that public attitudes can become more positive over time once new schemes become established (Sharp et al, 2010; Poortinga et al, 2013).

"In terms of waste let alone environmental issues as a whole this is a drop in the ocean."

"It's not the plastic bags that add to the rubbish in the environment, it's the plastic packaging used by the supermarkets!" 
Some participants suggested that the proliferation of plastic-bag litter in the environment could be attributed to consumers' behaviours and attitudes rather than because the bags were free of charge.

"The problem of discarded bags has nothing to do with the fact that they are free but down to the attitude of people to their environment and no matter how much you charge then for packaging they will just discard it on the ground."

Some suggested that the government was addressing the wrong issues by imposing a levy on single-use plastic bags rather than institutionalising the production of biodegradable or reusable plastic bags, including bin bags.

"I think charging for bags tackles the wrong issue."

"Whilst I agree that waste is an issue, it feels like we're focusing on the wrong details."

"Why not just tell all shops they must only use biodegradable bags?"

Further, participants felt that there might be little or no significant environmental benefits as a result of the levy on single-use carrier bags.

"There is no environmental gain by restricting plastic bags."

However, a significant amount of comments supported the idea and reckoned that the levy was a good strategy to address the increasing amount of plastic-bag waste that was defacing the landscape and causing environmental hazards.

"Great policy to get rid of unnecessary waste and a drain on public money having to clean up the results of this indulgence."

"It compensates for those who aren't environmentally-inclined enough to reuse bags. Good work!"

For the sake of the environment, other measures were proposed by the participants. These included changing packaging containers to re-fillable containers. 
"I reckon more good could be done for the environment by changing the packaging of products

exponentially and providing re-fillable containers where appropriate so one can just visit the

supermarket and refill them from dispensers of some kind."

Although the Scottish Environment Secretary reiterated in his speech that the levy was introduced to reduce

plastic bags, an estimated revenue of about $£ 5 \mathrm{~m}$ annually would be generated for good causes through the levy (BBC, 2013). If voluntary action between the retailers and consumers in Scotland had already reduced plastic-bag use by 40\%, as claimed by Scottish Retail Consortium (SRC, BBC 2013), imposing the levy for environmental reasons might be argued to be unjustified. This might crowd out the initial motivation behind the voluntary actions of reducing plastic-bag use in Scotland. As a result, it is suggested that decisionmakers and/or policy-makers should give pricing (such as a levy) less consideration when attempting to improve the environment and maximising performance (Frey, 1993), or, where a levy is necessary, consider focusing on other issues in their public communications. Using a non-market-based motivational approach such as awareness, adequate information (Evison \& Read, 2001) and performance feedback (Mee, Clewes, Phillips, \& Read, 2004) may be more effective in reducing plastic-bag use. The fact is that consumers are doing their bit and they should be compensated for their voluntary actions as the levy may introduce "costly additional red tape," as suggested by the Confederation of British Industry (CBI) Scotland.

\subsection{Perceived impact of the charge}

According to the CBI, the levy was necessitated due to the Scottish government's original intention of achieving a rapid and drastic $80 \%$ reduction in the amount of plastic bags being used or thrown away in Scotland. However, some participants were sceptical about the possible effects of a market-based approach in influencing consumers' behaviours toward plastic-bag use. As a result, some participants suggested that the imposition of a minimum charge on plastic-bag consumption would exert little or no effects on consumers' plastic-bag use.

"I don't think charging for bags makes a blind bit of difference." 
"This will make very little difference to most people."

On the other hand, some participants were of the opinion that the levy was too small to make any significant impact on consumers' plastic-bag use, suggesting that the charge might not be sufficient to discourage consumers from throwing out or littering with their bags after a single use.

"5p per bag is not going to deter anyone from using them."

"What is $5 p . .$. it will make no difference."

"I am afraid a 5p cost will not be a deterrent to those who throw away plastic bags."

Using a particular experience from Wales as an example, one participant argued further that the $5 \mathrm{p}$ levy would not discourage people from buying (and/or consuming) a single-use carrier (plastic) bags.

"I have spent time in Wales recently and everyone still appears to buy plastic bags."

As a result, raising the levy beyond the present $5 \mathrm{p}$ might have significant influence on consumers' behaviours. It was advocated by some that an increase above the current $5 \mathrm{p}$ levy would be required to deter people from purchasing a single-use carrier bag.

"Although I would probably raise the price beyond the $5 p$ level to really discourage the uptake of plastic bags."

For the levy to be an effective tool in influencing behavioural change, specific amounts were suggested by some participants. Charging beyond the current $5 \mathrm{p}$ therefore might enhance behavioural change and encourage consumers to re-use or use own bags while shopping.

“Why not make it $£ 1$, that would really make people think before they went shopping."

"The levy should be 20p. People would then use "bags for life" rather than "use once" and then throw away. I probably throw away 400 bags a year; at 20p a bag I think I might change my behaviour!”

However, other participants saw the minimum charge of $5 \mathrm{p}$ as reasonable and potentially effective.

"5p is a good amount to serve as a reminder without breaking the bank." 
"A charge of $5 p$ is enough to make most people get organised and carry bags with them."

"Anything that requires Scots spending an extra 5p certainly will work!"

Thus different perspectives emerged from the participants' comments. Whilst there was a feeling against the effectiveness of the levy, the levy was considered by some participants to be too small to influence behavioural change. The CBI, on behalf of retailers in Scotland, argued that the introduction of the levy would increase retail businesses' burdens:

"The plans for costly additional red tape in the form of an environmental levy on carrier bags, after significant success recently in reducing the use of plastic bags by voluntary means, will only make a difficult situation even tougher for retail businesses." (BBC, 2014).

\subsection{Suggested alternative legislative strategies}

Reflecting on the speech made by the Environment Secretary (BBC, 2014), with the information that Scotland consumes and probably throws away more plastic bags than any other country in the UK, it could make more environmental sense to completely abolish this "little devil". It may be a better solution not only for the retailers and consumers but also for the environment rather than imposing a minimum charge on consumers. This was an opinion shared by some participants.

"It was a much better solution than messing about with a 5p charge."

"Best option is to do away with plastic bags altogether."

Citing examples of different countries that had imposed bans on plastic bags, the participants challenged consumers' inability to use their own bags.

"Just get them banned!"

"If a country like Uganda can ban all plastic bags then surely British consumers have the ability to remember to take a shopping bag out when they go shopping." 
In addition, the Scottish government was criticised for not emulating other countries and adopting costeffective practices such as introducing biodegradable carrier bags.

"In Italy they passed a law banning the normal carrier bag and introduced a fast acting bio degradable carrier.... Which costs the public nothing. Why can't our governments do the same???"

"It's even simpler, ban all plastic bags and make manufacturers use only degradable packaging."

\subsection{Timing of the introduction of the charge}

This section aims to understand the perceptions of the participants regarding the timing of the strategy. The timing of the introduction of a levy may have either a positive or negative effect on its success.

Many participants perceived the strategy as well over due and felt that the levy should have been introduced earlier.

"It's about time really. This should have been implemented years ago."

"Well it's about time, they have a system like this in France and it works very well, people know they have to bring their own bags with them and they are not discarded all over the place."

Based on this perception, consumers would be more willing to support government initiatives in reducing the total amount of plastic bags in Scotland. On the one hand, the level of awareness may offer incentives to willingly support the initiative (Garcés et al. 2002) and strongly influence consumers' pro-environmental behaviour (Evison \& Read 2001; Grodzinska-Jurczak et al., 2006). On the other hand, the perceived importance of the scheme may likely manipulate consumers' ethical judgment and influence the consumers' intention to support the scheme by using their own bags. 


\subsection{Bag quality}

In order to ensure that the amount of plastic bags being used in Scotland was reduced, there was a necessity for improved quality compared to the quality of single-use carrier bags prior to the introduction of the levy. The rationale is to enhance the re-usability of the carrier bags and to ensure value for money. If our collective desire is to protect the environment then plastic bags and carrier bags should be produced with high standards so consumers could re-use instead of throwing away damaged bags after a single use. This was a consideration mentioned by several participants.

"Well better make sure that they are good quality carrier bags and not the cheap rubbish that burst as soon as any kind of weight is added."

"They'd be more environmentally friendly if they were made a little stronger."

No provision was made in the regulations for quality requirements and it was pointed out that consumers might demand a better quality bag.

"What will happen is we as shoppers will demand better quality bags for our $5 p$. ."

While some participants advocated for stronger plastic bags that could be re-used, others were of the opinion that plastic bags should be plain and free of any advert. Participants were particularly unhappy about the concept of paying for bags carrying retailers' branding.

"I have no problem paying for a plain carrier bag, but why should I pay to advertise a supermarket. Surely it should be illegal to charge people to advertise a shop."

"I'm not paying to give them free advertising!"

"Also, if the bags cost, they should be plain white, no advertising."

Nevertheless, participants were keen that the Scottish government enforced quality standards to assure that the bags are fit for purpose and could be re-used. This may impact on the propensity for throwing away carrier bags after a single use by consumers. 


\subsection{Secondary use (or reuse) of plastic bags}

This section addresses the subjective lived-experiences of participants concerning alternative methods of utilising already used single-use carrier bags. Understandably, the concepts of recycling and re-use are being misinterpreted and many people conceived these actions differently from their technical or legal descriptions. As observed from the participants' comments, most of the participants misconstrued the concept of recycling by attributing the alternative use of their plastic bags as another form of recycling behaviour rather than reuse.

"Most people use their plastic bags for many other things which is a form of recycling."

"We use supermarket plastic bags as bin bags, so in a way we were recycling them."

"I re-use and recycle ALL my plastic bags as bin liners, and therefore don't buy bin liners."

Thus carrier (especially single-use plastic) bags were being used for different purposes such as bin liners, bin bags and for other functions. These behaviours were perceived as recycling and/or reuse behaviours with the justification that nothing was wasted by finding other ways of utilising the single-use plastic bags.

"In our house plastic bags are used for; cleaning up after the dog, bin liners for bathroom/bedroom bins, carrying shoes/trainers to school, wet clothes after swimming, school PE kit, covering bike seat left in rain, packed lunches etc."

"I use carrier bags as bin liners, so none get wasted."

Some participants admitted that they deliberately asked for multiple bags with the intention of re-using them as bin liners, which they perceived as a means of re-use that may consequently reduce waste.

"On occasions I will deliberately ask for shopping bags as I use these as indoor bin liners (i.e. re-use them)."

"I don't mind at all re-using my weekly shopping bags, because such re-use is likely to cut litter." 
Thus people who had used their free single-use carrier bags as bin liners in the past might now be forced to purchase bin bags/liners and thus be less likely to support the levy.

"Most people reuse them for trash. So they'll either buy bin liners or there'll be more unwrapped rubbish."

"We have always used the bags for "bin-bags" if they are taxed we are going to have to purchase bags."

"Many of us use the bags for a variety of uses so now I will simply need to buy lots and lots of bin liners."

If these people are not using their own bags while shopping, purchasing bin liners as well as carrier bags may increase the total amount of plastic bags being utilised in Scotland. As a result, bin bags should be produced from biodegradable materials in order to reduce the impact of plastic bags on the environment with increasing numbers of them being accumulated in landfill.

"If you stop getting bags from shops you will have to buy bin bags which will still go to landfill."

Purchasing bin bags/liners instead of re-using single-use plastic bags was perceived to be anti-recycling by some participants.

"For us this is the opposite of recycling as now we will buy more plastic in terms of dog poo bags and small bin liners, how is that a good thing?"

"I have never thrown an empty plastic bag in the dustbin, it's always be utilised in some way."

However, re-using plastic bags in this way is counter-productive and may undermine the efforts of the Scottish government in reducing the proliferation of plastic bags in the environment. The fact is that singleuse plastic bags and bin liners may end up in landfill with detrimental effects on the environment. An awareness of this fact was demonstrated by some participants.

"Reusing as bin bags is a farce, I know people who get extra bags (free) to use for the bin, but buying recycled bin bags is best."

"Plastic carrier bag shouldn't be used as bin liners as they do not decompose, they last for centuries \& have a severe impact on our environment." 
As a result, it is suggested that the Scottish government through all the relevant agencies, especially SEPA (Scottish Environment Protection Agency), should completely eradicate non-biodegradable carrier bags as well as bin liners.

\section{Study Limitations}

This study has demonstrated the contribution and significance of a low-cost and time-efficient datacollection approach using internet websites and social-media sites in understanding consumers' proenvironmental behaviour toward plastic bags use in Scotland. One of the limitations of the approach is the potential problem of multiple responses from a single participant, especially when the quantity of responses is significant to the analysis. In addition, the lack of socio-demographic information made it impossible to identify the location, gender, age and other information about the participants. As a result, the sampling frame as well as the representativeness of the participants could not be established. In addition, sampling as well as measurement error could not be addressed as no particular question was addressed to the participants. Nevertheless, the quality rather than quantity of information is the basis of these present analyses. In total, 781 comments were posted on the "Have Your Say" message board, which highlights the amount of interest the introduction of the levy generated. However, only 764 comments were available for analysis and included in this research.

\section{Study Implications}

\subsection{Implications for Consumers}

The introduction of carrier-bag charges across the UK would undoubtedly exact significant effects on consumers; however, the major concern is how the charge would influence consumers' pro-environmental behaviours. Although there are mixed feelings about its introduction, the actual effects of carrier-bag charges on consumers' behaviours are still elusive. On the one hand, the consumption rate of carrier bags 
in the UK may be reduced without changing consumers' waste prevention (or recycling) behaviour. Unless the charge increases annually, it may attain a saturation point at which consumers would consider the 5p charge to be part of their shopping expenses. The incentives (such as avoiding a $5 \mathrm{p}$ charge) may not necessarily influence behaviour (Shaw \& Maynard, 2008) and behaviour may subsequently return to the baseline (Grodzinska-Jurczak et al., 2006) with an increase in the consumption of carrier bags, especially plastic bags. Using extrinsic incentives such as the $5 \mathrm{p}$ charge may be difficult in promoting a long-lasting behaviour (De Young, 1986). On the other hand, the behaviour (carrier-bag usage) may spill-over to other pro-environmental behaviours (Thøgersen, 2004) such as food-waste prevention when considered to be personal norm. This suggests the internalisation of extrinsic incentives to the point that consumers feel a moral obligation (Berglund, 2006) to prevent waste and are satisfied/enjoy carrying out the behaviour (De Young, 1986), which may instigate interest in other pro-environmental behaviours. While legal norms may be less effective in reinforcing behaviour, personal (moral) norms are observed to influence proenvironmental behaviour (Hage et al., 2009). Whatever the case may be, the $5 \mathrm{p}$ charge may provide incentives for immediate reduction of carrier-bag consumption in Scotland, which may subsequently improve the state of environmental health.

\subsection{Policy Implications}

The findings from this research suggest that a financial policy may not be sufficient in changing behaviours considering the mixed views of the participants on the carrier-bag charge in Scotland. As a result, a comprehensive policy that addresses economic, environmental, social, and political needs (Bratt, Stern, Matthies, \& Nenseth, 2014) may be required if an enduring change is to be achieved. The fact that packaging waste has not been effectively addressed could reduce the importance of a carrier-bag charge. For example supermarkets are still using excessive packaging materials (especially packaged food) (see Waste and Resources Action Programme, 2015) while consumers are not changing their behaviour (especially when buying loose fruit and meat), which may create a notion of double standards from policy 
perspectives. For any policy interventions to be effective, consumers should be considered as part of the solution to waste-management (prevention or recycling) efforts. As a result, the right mix of consumers' rights and moral obligations may be required to promote ethical behaviours by policy makers (Cherrier 2006). This could be achieved by integrating consumers' perspectives on the environment (and particularly waste management) into the policy process and its implementation. An understanding of consumers' environmental (and/or waste management) perspectives and its underlying factors may enhance policy formulation and implementation. Rather than enacting a policy that may transfer the environmental cost of products (such as carrier bags) to consumers, producers and retailers should play their parts in reducing the environmental burdens of these products. On the other hand, the UK government may consider a drastic measure, such as a complete ban on the production as well as the consumption of single-use plastic bags, if serious about the environment. The influence of restrictions and/or ban of plastic-bag usage on the environment is evident in the countries that have introduced such a policy (see Convery et al., 2007 for review).

\section{Summary and Conclusion}

This study of public perceptions of the use of a market instrument to reduce single-use carrier bag use gives important insights into how this measure is understood, framed and evaluated by the public, giving us an understanding of how and why this specific piece of legislation affects, or does not affect their behaviour. From these analyses, it is obvious that perceptions of consumers concerning single-use carrier bags, especially plastic bags, are mixed and often contradictory. In all, seven relevant themes were generated from the participants' subjective perceptions of the minimum $5 \mathrm{p}$ charge on a single-use carrier bag in Scotland. These themes are perceived to reflect the daily lived experiences of the participants concerning plastic or carrier-bag use. While some participants perceived the levy to be a good idea, others were cynical about its introduction, including the effects it may have on consumers. The data show that many of those who were against the levy were people who were using free bags for other domestic purposes such as bin 
liners. This finding was supported by Convery et al. (2007) who observed that those who were reusing shopping plastic bags for other purposes were more likely to criticise and oppose the Irish "Plastax". Although there is an inclination to consume excessive plastic bags when they are free (Ayalon et al., 2009), plastic bags are observed to be consumed for other purposes than grocery shopping (Cherrier, 2006).

Rather than donating the money to charity organisations, this research suggests that it might be more popular if the proceeds were used in addressing environmental issues such as fly-tipping in Scotland instead of using tax-payers' money. This is based on the understanding that around 60,000 incidents of fly-tipping are reported in Scotland each year and with a direct cost of around $£ 8.9$ million (Zero Waste Scotland, 2013). In addition, the findings of this research suggest that a higher number of the participants perceived the levy to be too low and thus the levy may not make a significant impact in changing consumers' behaviours toward plastic carrier bags. The effects of this levy on consumers' bin bags/liners purchasing behaviours have not been empirically verified and may be of further research interest. Similarly, it is difficult to estimate the actual amount of plastic bags being consumed and dispatched to landfill without longitudinal, systematic examination of the content of litter and landfill. While authorities across the world have published the consumption as well as disposal rate of plastic bags, the data collection approach was not explicitly available (Chung, 2008). As a result, the perceived environmental effect of plastic bags may be political rather than environmental (Ayalon et al., 2009). If the charge is meant to reduce the environmental and social costs of manufacturing and disposal of carrier bags, it would be more acceptable to levy producers/retailers rather than consumers. However, "people must understand that the throwaway consumer society is a thing of the past" as noted by a participant.

The introduction of a levy in Scotland may reduce the health and environmental effects of plastic littering. Although anecdotal evidence suggests that there was about $80 \%$ reduction in plastic-bag use after six months of introducing the levy in Scotland, using a market-based approach may attract both positive and negative effects. No matter the case, public participation in the scheme is necessary for its success, and this may involve a complete behavioural change. Further empirical research may be required to fully unpack 
consumers' perceptions, including consumers' buying behaviours since the introduction of the levy. Such research should investigate the effects of the levy on the environment and its financial implications on consumers using the annual consumption rate of plastic bags before the levy's introduction as a baseline.

Further, longitudinal research will be necessary for a number of reasons. Firstly, experience from other countries has shown that consumer perceptions of schemes aimed at reducing single use carrier bag use tend to be more positive following their introduction than before (Sharp et al, 2010; Poortinga et al's (2013). Secondly, work in South Africa suggests that the effect of a levy may wear off over time (Dikgang, Leiman \& Visser, 2012).

\section{References}

Adane, 1., \& Muleta D. (2011). Survey on the usage of plastic bags, their disposal and adverse impacts on environment: A case study in Jimma City, Southwestern Ethiopia. Journal of Toxicology and Environmental Health Sciences, 3(8), 234-248.

Ayalon, O., Goldrath T., Rosenthal G., \& Grossman M. (2009). Reduction of plastic carrier bag use: An analysis of alternatives in Israel. Waste Management, 29(7), 2025-2032. doi: 10.1016/j.wasman.2009.02.016.

Beard, N.D. (2008) The Branding of Ethical Fashion and the Consumer: A Luxury Niche or Mass-market Reality?, Fashion Theory, 12:4, 447-467

Bell, K., \& Cave, S. (2011). Comparison of environmental impact of plastic, paper and cloth bags. Research and Library Service Briefing Note, Northern Ireland Assembly. Retrieved March 20, 2015 from: http://www.niassembly.gov.uk/globalassets/documents/raise/publications/2011/environment/3611.pdf.

Berglund, C. (2006). The assessment of households' recycling costs: The role of personal motives. Ecological Economics, 56(4), 560-569. doi: 10.1016/j.ecolecon.2005.03.005. 
Bratt, C., Stern, P.C., Matthies, E., \& Nenseth, V. 2014. Home, car use, and vacation: The structure of environmentally significant individual behavior. Environment and Behavior, 47(4), 436-473. doi: $10.1177 / 0013916514525038$.

British Broadcasting Corporation (2014). Minimum charge for carrier bags in Scotland introduced. Retrieved February 15, 2015 from: http://www.bbc.co.uk/news/uk-scotland-29677458.

Bryman, A. (2012). Social research methods. Oxford University Press.

Cherrier, H. (2006). Consumer identity and moral obligations in non-plastic bag consumption: A dialectical perspective. International Journal of Consumer Studies, 30(5). 515-523. doi: 10.1111/j.14706431.2006.00531.x.

Chida, M. (2011) Sustainability in Retail: The Failed Debate around Plastic Shopping Bags, Fashion Practice, 3:2, 175-196.

Chung, S.S. (2008). Using plastic bag waste to assess the reliability of self-reported waste disposal data. Waste Management, 28(12), 2574-2584. doi: 10.1016/j.wasman.2008.01.002.

Clapp, J., \& Swanston, L. (2009). Doing away with plastic shopping bags: international patterns of norm emergence and policy implementation. Environmental Politics, 18(3), 315-332. doi: $10.1080 / 09644010902823717$.

Convery, F., McDonnell, S., \& Ferreira, S. (2007). The most popular tax in Europe? Lessons from the Irish plastic bags levy. Environmental and Resource Economics, 38(1), 1-11. doi: 10.1007/s10640-006-9059-2.

Davidson, S., Martin, C., \& Treanor, S. (2009). Scottish environmental attitudes and behaviours Survey 2008 - Technical report. Edinburgh: Scottish Government. Retrieved December 10, 2014 from: http://www.scotland.gov.uk/Publications/2009/08/03100422/0.

De Young, R. (1986). Some psychological aspects of recycling the structure of conservation-satisfactions. Environment and behavior, 18(4), 435-449. doi: 10.1177/0013916586184001. 
De Young, R., \& Kaplan, S. (1988). On averting the tragedy of the commons. Environmental Management, 12(3). 273-283. doi: 10.1007/BF01867519.

Department for Environment, Food and Rural Affairs, Environment Agency (2009). Environmental protection - Recycling and waste. Retrieved March 24, 2015 from: http://archive.defra.gov.uk/environment/waste/topics/plastics.

Department for Environment, Food and Rural Affairs, Environment Agency (2015). Carrier bags: Why there's a charge. Retrieved November $10, \quad 2015$ from: https://www.gov.uk/government/publications/single-use-plastic-carrier-bags-why-were-introducing-thecharge/carrier-bags-why-theres-a-5p-charge.

Department of the Environment (2013). Carrier bag levy: Regulatory impact assessment. Retrieved March 26, 2015 from: http://www.doeni.gov.uk/carrier_bag_levy__regulatory_impact_assessment_ria_2013.pdf.

Department of the Environment (2014). The first set of official Carrier Bag Levy statistics covering the period 8 April 2013 to 31 March 2014. Retrieved March 26, 2015 from: http://www.northernireland.gov.uk/news-doe-270814-first-carrier-bag.

Department of the Environment, Community and Local Government (undated). Plastic Bags. Retrieved March 26, 2015 from: http://www.environ.ie/environment/waste/plastic-bags/plastic-bag-levy.

Dikgang, J., Leiman, A., \& Visser, M. (2012). Analysis of the plastic-bag levy in South Africa. Resources, Conservation and Recycling, 66, 59-65.

Ebreo, A., \& Vining, J., 2001. How similar are recycling and waste reduction? Future orientation and reasons for reducing waste as predictors of self-reported behavior. Environment and Behavior, 33(3), 424448. doi: $10.1177 / 00139160121973061$.

Edwards, C., \& Meyhoff, J. (2011). Life cycle assessment of supermarket carrier bags: A review of the bags available in 2006 [Report SC 030148]. Bristol: Environment Agency. Retrieved March 15, 2015 from: 
https://www.gov.uk/government/uploads/system/uploads/attachment_data/file/291023/scho0711buan-e-

e.pdf.

Evison, T., \& Read, A.D. (2001). Local Authority recycling and waste-awareness publicity/promotion. Resources, Conservation and Recycling, 32(3). 275-291. doi: 10.1016/S0921-3449(01)00066-0.

Frey, B.S. (1993). Motivation as a limit to pricing. Journal of Economic Psychology, 14(4), 635-664. doi: 10.1016/0167-4870(93)90014-c.

Garcés, C., Lafuente, A., Pedraja, M., \& Rivera, P. (2002). Urban waste recycling behavior: antecedents of participation in a selective collection program. Environmental management, 30(3), 378-390. doi: $10.1007 / \mathrm{s} 00267-002-2601-2$

Gilg, A., Barr, S., \& Ford, N. (2005). Green consumption or sustainable lifestyles? Identifying the sustainable consumer. Futures, 37(6), 481-504.

Gowen, A. (2010) D.C. Bags Wasteful Shopping Habit with Tax on Paper and Plastic. WASH.

POST, Jan. 2, 2010. Retrieved June 24, 2016 from http://www.washingtonpost.com/wpdyn/content/article/2010/01/01/AR2010010101673.html.

Grodzińska-Jurczak, M., Tomal, P., Tarabuła-Fiertak, M., Nieszporek, K., \& Read, A.D. (2006). Effects of an educational campaign on public environmental attitudes and behaviour in Poland. Resources, Conservation and Recycling, 46(2), 182-197. doi: 10.1016/j.resconrec.2005.06.010.

Hage, O., Söderholm, P., \& Berglund, C. (2009). Norms and economic motivation in household recycling: empirical evidence from Sweden. Resources, Conservation and Recycling 53(3), 155-165. doi: 10.1016/j.resconrec.2008.11.003.

Jakovcevic, A., Steg, L., Mazzeo, N., Caballero, R., Franco, P., Putrino, N., \& Favara, J. (2014). Charges for plastic bags: Motivational and behavioral effects. Journal of Environmental Psychology, 40, 372-380. 
Larsen, J., \& Venkova, S. (2014). The downfall of the plastic bag: A global picture. Retrieved March 25, 2015 from: http://www.earth-policy.org/plan_b updates/2014/update123.

Lessig, L. (2004). Free culture: How big media uses technology and the law to lock down culture and control creativity. New York: The Penguin Press. doi: 10.5860/choice.42-1641.

Lewis, H., Verghese, K., \& Fitzpatrick, L. (2010). Evaluating the sustainability impacts of packaging: the plastic carry bag dilemma. Packaging Technology and Science, 23(3), 145-160. doi: 10.1002/pts.886.

Luis, I. P., \& Spinola, H. (2010). The influence of a voluntary fee in the consumption of plastic bags on supermarkets from Madeira Island (Portugal). Journal of Environmental Planning and Management, 53(7), 883-889.

Markham, A., \& Buchanan, E. (2012). Ethical decision-making and Internet research (version 2.0): Recommendations from the AoIR Ethics Working Committee. Retrieved March 4, 2015 from: http://www.aoir.org/reports/ethics2.pdf.

Mee, N., Clewes, D., Phillips, P.S., \& Read, A.D. (2004). Effective implementation of a marketing communications strategy for kerbside recycling: a case study from Rushcliffe, UK. Resources, Conservation and Recycling, 42(1), 1-26. doi:10.1016/j.resconrec.2003.12.003.

Meriem, C., \& He, L. (2011). Sustainability: beyond recycling an exploratory study of retailers' environmental efforts in the USA. Journal of Business and Retail Management Research, 5(2).

Musa, H.M., Hayes, C., Bradley, M.J., Clayson, A., \& Gillibrand, G. (2013). Measures aimed at reducing plastic carrier bag use: A consumer behaviour focused study. Natural Environment, 1(1), 17-23. doi: 10.12966/ne.06.02.2013.

Ohtomo, S., \& Ohnuma, S. (2014). Psychological interventional approach for reduce resource consumption: Reducing plastic bag usage at supermarkets. Resources, Conservation and Recycling, 84, 57-65. 
Poortinga, W., Whitmarsh, L., \& Suffolk, C. (2013). The introduction of a single-use carrier bag charge in Wales: Attitude change and behavioural spillover effects. Journal of Environmental Psychology, 36, 240247. doi: 10.1016/j.jenvp.2013.09.001.

Priestley, S. (2016). Household recycling in the UK. Briefing Paper Number CBP 7285. The House of Commons Library, House of Parliament UK. Retrieved March 15, 2016 from: http://researchbriefings.files.parliament.uk/documents/CBP-7285/CBP-7285.pdf.

Quinlan, S., Shephard, M., \& Paterson, L. (2015). Online discussion and the 2014 Scottish independence referendum: Flaming keyboards or forums for deliberation?. Electoral Studies, 38, 192-205. doi: 10.1016/j.electstud.2015.02.009.

Ritch, E., Brennan, C., \& MacLeod, C. (2009). Plastic bag politics: modifying consumer behaviour for sustainable development. International Journal of Consumer Studies, 33(2), 168-174. doi: 10.1111/j.14706431.2009.00749.x.

Ritchie, J., Lewis, J., Nicholls, C.M., \& Ormston, R. (Eds.). (2013). Qualitative research practice: A guide for social science students and researchers. Sage.

Rosen, J. (2006). The people formerly known as the audience. PressThink blog.

Rowe, G., Hawkes, G., \& Houghton, J. (2008). Initial UK public reaction to avian influenza: Analysis of opinions posted on the BBC website. Health, risk and society, 10(4), 361-384. doi: $10.1080 / 13698570802166456$.

Scottish Parliament (2014). The Single Use Carrier Bags Charge (Scotland) Regulations 2014. Retrieved January 20, $2015 \quad$ from: http://www.legislation.gov.uk/sdsi/2014/9780111023211/pdfs/sdsi_9780111023211_en.pdf.

Shanahan, M.C. (2010). Changing the meaning of peer-to-peer? Exploring online comment spaces as sites of negotiated expertise. Journal of Science Communication, 9(1), 1-13. 
Sharp, A., Høj, S. \& Wheeler, M. (2010). Proscription and its impact on anti-consumption behaviour and attitudes: the case of plastic bags. Journal of Consumer Behaviour, 9(6), .470-484. doi: 10.1002/cb.335

Shaw, P.J., \& Maynard, S.J. (2008). The potential of financial incentives to enhance householders' kerbside recycling behaviour. Waste Management, 28(10), 1732-1741. doi: 10.1016/j.wasman.2007.08.008.

Shephard, M. P., Quinlan, S., Tagg, S., \& Paterson, L. (2014). Engaging the brain as well as the heart: Political literacy and social media platforms, In A. Mycock \& J. Tonge (Eds.), Beyond the Youth Citizenship Commission: Young people and politics (pp. 37-41). London: Political Studies Association.

Synthia, I. J., \& Kabir, S. (2015). An Investigation of Cosumer Attitudes Towards New Varieties of Shopping Bags: Exploring Eco-Awareness and the Possibility of Behavior Change. The Journal of Developing Areas, 49(5), 183-196.

Thøgersen, J., \& Crompton, T. (2009). Simple and painless? The limitations of spillover in environmental campaigning. Journal of Consumer Policy, 32(2), 141-163. doi: 10.1007/s10603-009-9101-1.

Thøgersen, J. (2004). A cognitive dissonance interpretation of consistencies and inconsistencies in environmentally responsible behavior. Journal of Environmental Psychology, 24(1), 93-103. doi: 10.1016/s0272-4944(03)00039-2.

Waste and Resources Action Programme (2012). UK supermarket retailers voluntary carrier bag agreement: 2011 carrier bag use. Retrieved March 4, 2015.from: http://www.wrap.org.uk/sites/files/wrap/Carrier\%20Bag\%20Results.pdf.

Waste and Resources Action Programme (2015). Estimates of Food and Packaging Waste in the UK Grocery Retail and Hospitality Supply Chains. Retrieved May 10, 2016 from: http://www.wrap.org.uk/sites/files/wrap/UK\%20Estimates\%20October\%2015\%20\%28FINAL\%29 0.pdf

WorldWatch Institute (2004). The state of the world: A Worldwatch Institute Report on progress toward a sustainable society. Washington, DC: Worldwatch Institute. doi: 10.4324/9781315065694. 
Zero Waste Scotland (2014). The Single Use Carrier Bag Charge (Scotland) Regulations 2014: Guidance for Retailers. $\quad$ Retrieved $\quad$ March 2015 from: http://carrierbagchargescotland.org.uk/includes/resources/Retail_Guidance Single_Use_Carrier_Bag_Ch arge_Scotland_Regulation.pdf.

Zero Waste Scotland (2013). Scotland's litter problem: Quantifying the scale and cost of litter and $\begin{array}{lllll}\text { flytipping. } & \text { Retrieved } & \text { October } & 2015 & \text { from: }\end{array}$ http://www.zerowastescotland.org.uk/content/scotland $\% E 2 \% 80 \% 99$ s-litter-problem-0.

Zero Waste Scotland (2015). Carrier bag charge 'one year on'. Retrieved November 15, 2015 from: http://www.zerowastescotland.org.uk/sites/default/files/SUCB $\% 20$ Charge $\% 200$ ne $\% 20$ Year\%20On\%20R eport.pdf.

Zero Waste Scotland (2014) 'Carrier Bag Charge: Reducing litter and waste through good legislation' Retrieved June 08, 2017 from: http://www.zerowastescotland.org.uk/litter-flytipping/carrier-bag-charge. 